\title{
Frontline therapies for untreated chronic lymphoid leukemia
}

\author{
Delong Liu ${ }^{1,2^{*}}$ and Juanjuan Zhao ${ }^{2}$
}

\begin{abstract}
Therapy for chronic myeloid leukemia (CLL) is going through a major paradigm shift. Combination chemoimmunotherapy regimens have been the frontline therapies for $C L L$, whereas chlorambucil remained the standard frontline therapy for older patients ( 65 years or older) with CLL until recently. Monoclonal antibodies including rituximab, ofatumumab and obinutuzumab have been used for CLL therapy. Novel immunotherapeutics with chimeric antigen receptor (CAR) engineered T cells is rapidly migrating to clinical applications. Targeted therapies with small molecule inhibitors against Bruton tyrosine kinase (BTK) such as ibrutinib and acalabrutinib are playing a major role for treatment of patients with either treatment-naïve or refractory/relapsed CLL. Several major clinical trials including RESONATE-2, iLLUMINATE, ALLIANCE, ECOG 1912, CLL10, CLL14 as well as ibrutinib plus venetoclax have been ongoing in patients with untreated CLL. Frontline therapy of patients with untreated CLL appears to be shifting from chemotherapy to chemotherapy-free regimens. This review summarized latest development for frontline therapies of untreated CLL.
\end{abstract}

Keywords: Chronic lymphoid leukemia, Venetoclax, Ibrutinib, ALLIANCE, iLLUMINATE, RESONATE-2

\section{Background}

Therapy for chronic myeloid leukemia (CLL) is going through a major paradigm shift [1-3]. Combination chemoimmunotherapy regimens like FCR (fludarabine, cyclophosphamide, rituximab) and BR (bendamustine, rituximab) have been the frontline therapies for CLL, whereas chlorambucil remained the standard frontline therapy for older patients (65 years or older) with CLL until recently $[4,5]$. Monoclonal antibodies including rituximab, ofatumumab and obinutuzumab have been used for CLL therapy [6, 7]. Novel immunotherapeutics with chimeric antigen receptor (CAR) engineered $\mathrm{T}$ cells is rapidly migrating to clinical applications [8-17]. Targeted therapy with small molecule inhibitors against Bruton tyrosine kinase (BTK) such as ibrutinib and acalabrutinib are playing a major role for treatment of patients with either treatment-naïve or refractory/relapsed CLL [18-22]. Several major clinical trials have been ongoing

\footnotetext{
*Correspondence: delong_liu@nymc.edu

1 Division of Hematology \& Oncology, New York Medical College, Valhalla, NY 10595, USA

Full list of author information is available at the end of the article
}

in patients with treatment-naïve CLL (TN CLL) [1]. Frontline therapy of patients with TN CLL appears to be shifting from chemotherapy to chemotherapy-free regimens. This review summarized latest development for frontline therapy of untreated CLL (Table 1).

\section{RESONATE-2 trial: ibrutinib vs chlorambucil}

Traditionally chlorambucil was the standard agent for frontline therapy of elderly patients $(>65)$ with CLL [23, 24]. Ibrutinib was compared with chlorambucil in a phase 3 randomized multicenter international study, RESONATE-2, in untreated older patients ( $\geq 65$ years) with CLL/SLL [25]. Patients with chromosome 17p13.1 deletion were excluded in this trial. PFS (progression free survival) was the primary end point. 269 patients with a median age of 73 were enrolled. Among these patients, 136 received ibrutinib (420 mg daily), 133 received chlorambucil. The median follow-up was 18.4 months. Ibrutinib led to a significant increase in PFS over chlorambucil (median, not reached vs. 18.9 months), with a hazard ratio of $0.16, \mathrm{P}<0.001$. What is more striking is that ibrutinib as a single oral agent significantly prolonged OS. The relative risk of death for patients in the ibrutinib

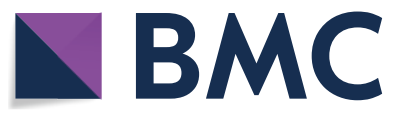

(c) The Author(s) 2019. This article is distributed under the terms of the Creative Commons Attribution 4.0 International License (http://creativecommons.org/licenses/by/4.0/), which permits unrestricted use, distribution, and reproduction in any medium, provided you give appropriate credit to the original author(s) and the source, provide a link to the Creative Commons license, and indicate if changes were made. The Creative Commons Public Domain Dedication waiver (http://creativecommons.org/ publicdomain/zero/1.0/) applies to the data made available in this article, unless otherwise stated. 


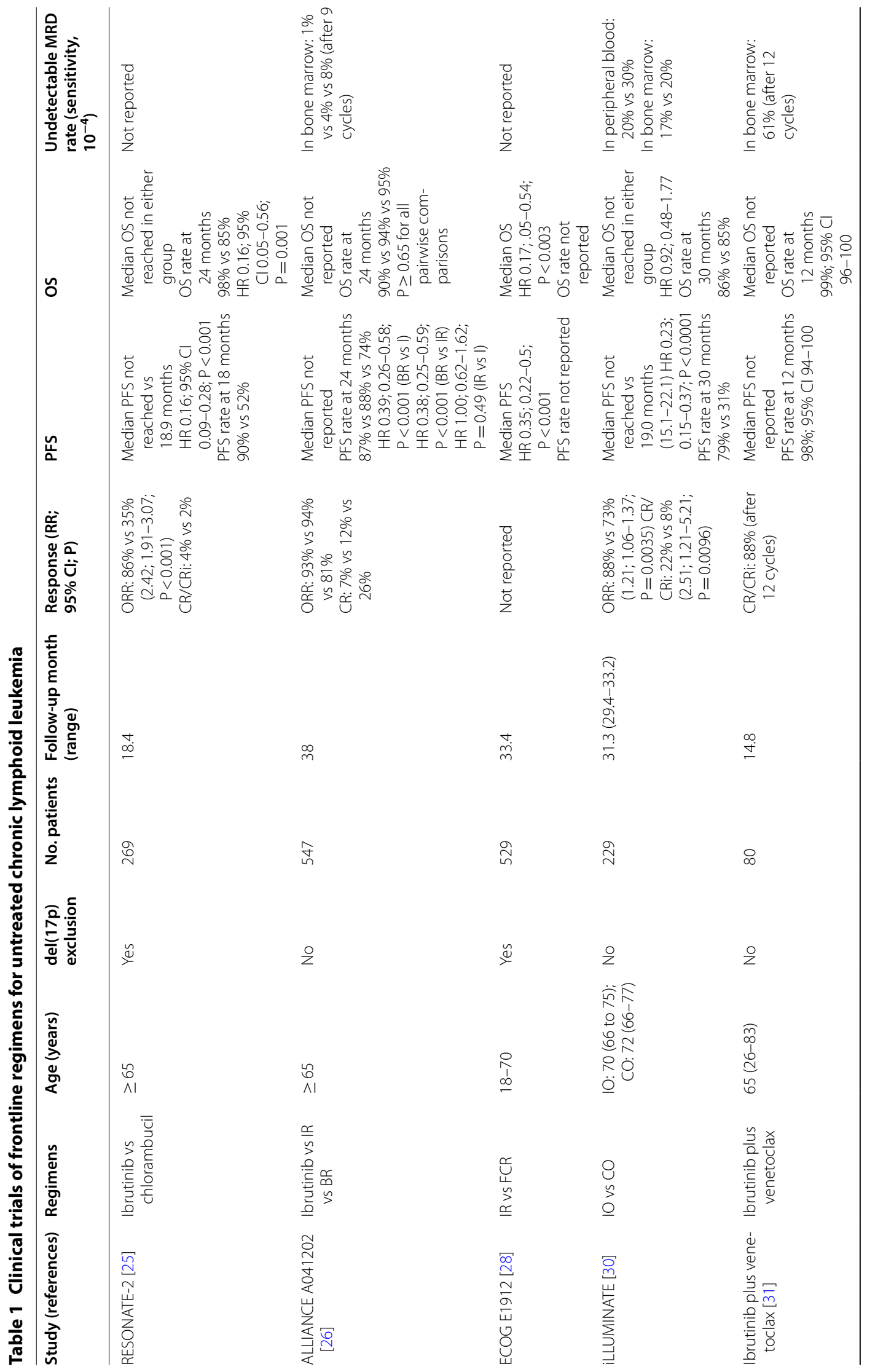




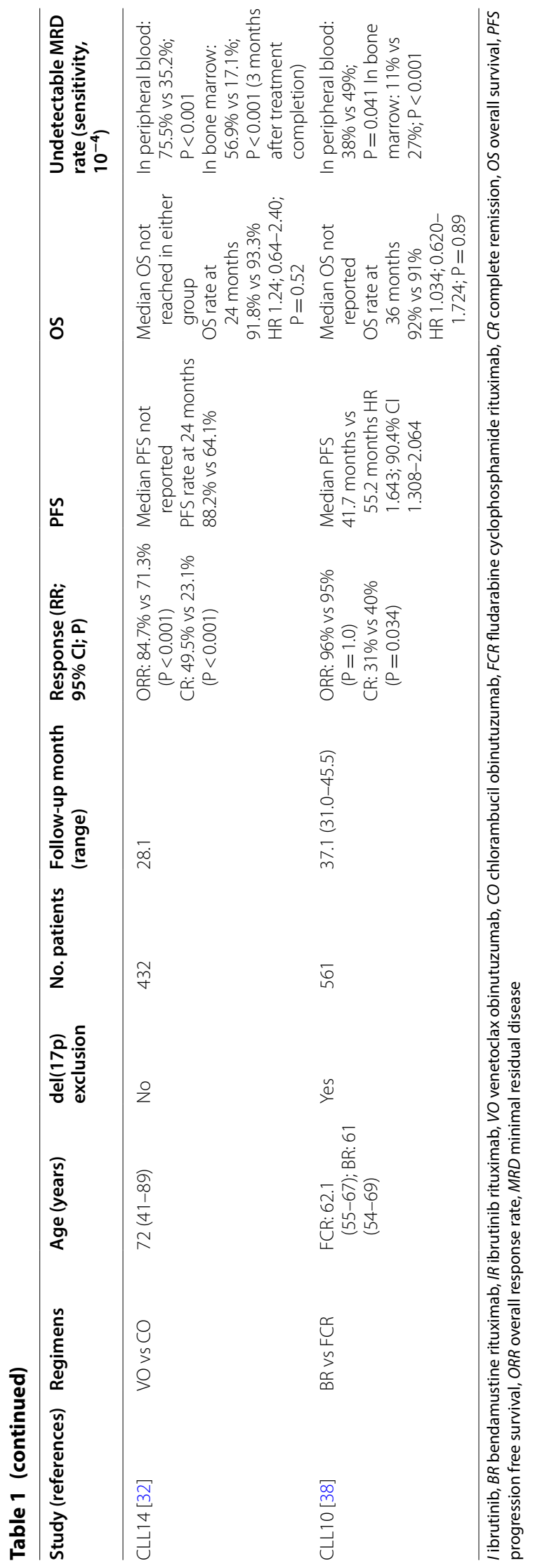


group was $84 \%$ lower than that in the chlorambucil group (hazard ratio, $0.16 ; \mathrm{P}=0.001$ ). Ibrutinib was also found to have significantly higher ORR than chlorambucil ( $86 \%$ vs. $35 \%, \mathrm{P}<0.001)$. Severe hemorrhage was reported in 5 patients who received ibrutinib. Atrial fibrillation was observed in $6 \%$ of the patients who were taking ibrutinib over the period of 1.5 years. Hypertension was also found to be more frequent than those in the chlorambucil group. Therefore, in previously untreated older patients with CLL/SLL, ibrutinib was confirmed to be significantly better than chlorambucil in OS, PFS and ORR. The RESONATE-2 study for the first time placed ibrutinib as the standard frontline oral agent for this population of patients with CLL/SLL.

\section{ALLIANCE A041202 trial: ibrutinib vs ibrutinib/ rituximab (IR) vs bendamustine/rituximab (BR)}

Ibrutinib as a single agent was compared with bendamustine plus rituximab (BR) and ibrutinib plus rituximab (IR) in patients ( $\geq 65$ years) with untreated CLL/SLL in a phase 3, randomized study, the ALLIANCE A041202 trial [26]. PFS was the primary end point. A total of 547 patients were enrolled, including 182 in the ibrutinib group, 182 in IR group, and 183 in the BR group. Median PFS was still not reached for the ibrutinib and IR groups at the time of this publication. The PFS at 2 years for the groups were $74 \%$ BR, $87 \%$ ibrutinib, and $88 \%$ IR. Compared with BR, the risk of death or disease progression was reduced by $61 \%$ in the ibrutinib group $(\mathrm{HR}=0.39$; 95\% confidence interval [CI] 0.26 to $0.58 ; \mathrm{P}<0.001)$, and by $62 \%$ in the IR group (HR $=0.38$; $95 \%$ CI 0.25 to 0.59 ; $\mathrm{P}<0.001)$. PFS remained similar between ibrutinib and IR groups. Therefore, for patients with CLL and age 65 or older, continuous ibrutinib as well as IR was shown to be superior to six cycles of BR as assessed by PFS, though OS were similar among the three groups. It was postulated from in vitro studies that ibrutinib suppresses antibody-dependent cellular cytotoxicity, thereby rendering rituximab ineffective when the two were combined. This may explain in part that ibrutinib and IR had similar PFS. It is important to point out that at the time the study was designed, patients with chromosome $17 \mathrm{p}$ deletion were not excluded in this trial. It is clear now that these patients are inappropriate for BR therapy $(n=14$ in the BR group), though patients who progressed in the BR group were allowed to cross over to receive ibrutinib. Atrial fibrillation of grade 3 and 4 was reported to be $3 \%$ in BR group, $9 \%$ in ibrutinib group, and $6 \%$ in IR group. The ALLIANCE study again independently confirmed that ibrutinib as a single agent is superior to BR combination regimen in this group of untreated older CLL patients in PFS.

\section{ECOG E1912 trial: ibrutinib/rituximab vs FCR (fludarabine, cyclophosphamide, rituximab)}

FCR remains as the most active regimen in CLL/SLL patients younger than 70 years of age [27]. However, the median age of CLL/SLL patients are over 65. In addition, ibrutinib as a single agent is usually given continuously until disease progression or development of significant toxicity. Therefore, patients with CLL/SLL between age 18-70 were randomized to receive IR (ibrutinib/rituxi$\mathrm{mab})$ or FCR in a 2:1 ratio [28]. Patients with chromosome 17p13.1 deletion were excluded in this trial. The primary end point was PFS, OS was the secondary end point. 529 patients were enrolled, with 354 patients in the IR group, and 175 in the FCR group. The median followup was 33.4 months. IR led to a $65 \%$ reduction in the risk of disease progression or death in comparison with FCR $(\mathrm{HR}=0.35 ; 95 \% \mathrm{CI} 0.22-0.5 ; \mathrm{P}<0.001)$. IR also significantly prolonged OS, with $\mathrm{HR}=0.17$ (95\% CI 0.05-0.54; $\mathrm{P}<0.003)$. Furthermore, IR regimen is significantly less toxic than FCR, since severe TEAE (treatment-emerging adverse event) in FCR group (72\%) was significantly more frequent than that in the IR group $(58 \%)(\mathrm{P}=0.0042)$.

In the subgroup analysis, patients with unmuted IGHV benefited more from IR than from FCR, with reduction of risk of death or disease progression by 74 percent by IR $(\mathrm{HR}=0.26$; 95\% CI 0.14-0.5; $\mathrm{P}<0.0001)$.

Therefore, in untreated patients with CLL/SLL, IR is superior to FCR in terms of PFS and OS as well as in therapy toxicity.

\section{iLLUMINATE trial: ibrutinib/obinutuzumab (IO) vs chlorambucil/obinutuzumab (CO)}

Chlorambucil/obinutuzumab (CO) combination was shown to be superior to chlorambucil plus rituximab in CLL patient with comorbidities [29]. IO was compared to $\mathrm{CO}$ in an international, multicenter, randomized, openlabel, phase 3 trial, iLLUMINATE, in untreated CLL/ SLL patients $\geq 65$, or younger patients with co-morbidities [30]. The primary end point was PFS. A total of 229 patients were enrolled, including 113 in IO group, and 116 in CO group. The median follow-up was 31.3 months (29.4-33.2). PFS in the IO group was significantly longer than that in $\mathrm{CO}$ group $(\mathrm{HR}=0.23,95 \% \mathrm{CI} 0.15-0.37$, $\mathrm{P}<0.0001)$. Severe neutropenia and thrombocytopenia were the most common adverse events in both groups. Therefore, this chemotherapy-free combination regimen, IO, is a good option of frontline therapy in this group of older CLL/SLL patients or younger patient with co-morbidities. At this time, it is unclear whether $\mathrm{IO}$ is superior to ibrutinib alone. The rates of $\mathrm{CR}$ and undetectable minimal residual disease (MRD) appeared to favor IO combination over single agent ibrutinib, though the two have not been directly compared in a randomized trial. 


\section{Ibrutinib plus venetoclax}

Since ibrutinib and venetoclax have distinct mechanisms of action, the two may have synergistic activities. Ibrutinib and venetoclax as two oral agents were studied in a phase 2 trial in untreated CLL patients with one or more of the high risk features: chromosome $17 \mathrm{p}$ deletion, mutated TP53, chromosome 11q deletion, unmutated IGHV, 65 years or older [31]. To minimize the risk of tumor lysis, ibrutinib monotherapy at $420 \mathrm{mg}$ daily were given for 3 cycles prior to combination with venetoclax (weekly dose escalation up to $400 \mathrm{mg}$ once daily). The combination treatment was continued for 24 months. A total of 80 patients were enrolled, with a median age of 65 years (26-83 years). Responses to the combined treatment continued to improve over time and were noted across all subgroups with high-risk features. High CR/CRi were observed at $88 \%$ after 12 cycles of combined therapy, and $61 \%$ had deep remission with undetectable MRD which was assessed by means of multicolor flow cytometry in bone marrow (sensitivity, $10^{-4}$ ). Laboratory TLS was seen in three patients. This chemotherapy-free oral regimen appeared to be highly effective in the phase 2 trial for high-risk untreated CLL patients. Further randomized study is needed.

\section{CLL14 trial: venetoclax plus obinutuzumab (VenG) vs chlorambucil plus obinutuzumab (CO)}

Venetoclax plus obinutuzumab (VenG) was compared with $\mathrm{CO}$ in previously untreated patients with CLL and comorbidities [32]. The treatment was given for a total of 12 cycles, with obinutuzumab for the first 6 cycles only. The primary end point was PFS, and the secondary end point was MRD negativity in the peripheral blood (PB) or bone marrow (BM) 3 months after completion of therapy. MRD was assessed every 3 months starting from cycle 4 by PCR and by next generation sequencing. A total of 432 patients were enrolled, with 216 in each arm. The median follow-up was 29 months. VenG was superior to CO in PFS (HR 0.35; 95\% CI $0.23-0.53 ; \mathrm{P}<0.0001)$ as well as in MRD negativity in both $\mathrm{PB}(76 \%$ vs $35 \%[\mathrm{P}<0.0001])$ and $\mathrm{BM}(57 \%$ vs $17 \%$ $[\mathrm{P}<0.0001])$. MRD negativity correlated with longer PFS. This correlation has been suggested in several analysis [33-36]. VenG induced higher and more sustainable MRD negativity. Therefore, this regimen represents the only fixed-duration chemotherapy-free treatment for untreated CLL with comorbidities [37]. Based on this CLL14 trial, this VenG regimen is now approved by FDA for first-line therapy of CLL/SLL.

\section{CLL10: BR vs FCR}

Both BR and FCR have been used as frontline therapy for CLL/SLL, with FCR approved for younger patients whereas BR appears to have less toxicity. BR and FCR were compared in a randomized study, CLL10 [38]. Patients with $17 \mathrm{p}$ deletion were excluded. The primary end point was PFS. CLL10 was a non-inferiority trial. The intention-to-treat analysis was done in 561 eligible patients, including 282 patients in the FCR group and 279 in the BR group. The median follow-up was 37.1 months (range 31.0-45.5). The PFS for BR group was 41.7 months (95\% CI 34.9-45.3) and 55.2 months (95\% CI not reached) for FCR group (HR 1.643, 90.4\% CI 1.308-2.064). Severe neutropenia and infection were more common in the FCR group. It appeared that in this group of clinically fit patients with untreated CLL, FCR is superior to BR and remains as the standard chemotherapy regimen, though BR is associated with less toxicity.

\section{Choice of a frontline regimen and special considerations}

For treatment-naïve CLL patients with p53 mutation or $17 p$ deletion, ibrutinib or chemotherapy-free regimen with venetoclax plus obinutuzumab (VenG) remains the preferred choice of therapy. For those untreated patients without p53 mutation or 17p deletion, based on data from the studies discussed above, NCCN guidelines (nccn.org) suggested ibrutinib as the preferred regimen. For frail patients with significant comorbidities or patients $>65$ years of age, chemotherapy-free regimen with VenG can be considered as a preferred alternative. A variety of alternative regimens are available for considerations.

Additional clinical situations may warrant further careful considerations for making a reasonable choice of frontline regimen. For example, for a patient who is on anticoagulation for atrial fibrillation and/or venous thrombosis, it may be prudent to consider VenG instead of ibrutinib so that risk of bleeding can be minimized. Patients frequently ask how long the treatment will last at the initial discussion of therapy options. Currently ibrutinib therapy does not have a clear timeline for treatment termination. Therefore, if a patient wishes to only take a limited time of therapy, VenG is the only regimen to have a fixed 12-cycle duration.

\section{Conclusion}

Small molecule BTK inhibitor, ibrutinib, is playing a central role in frontline therapy of untreated CLL since several major trials as outlined above provided evidence that ibrutinib as a single agent can be considered as the 
frontline therapy. Recently venetoclax plus obinutuzumab regimen has been approved as the first chemotherapy-free frontline therapy for untreated CLL with a fixed duration. Additional agents such as acalabrutinib are also under clinical trials for frontline therapy of untreated CLL $[20,39,40]$.

\begin{abstract}
Abbreviations
I: ibrutinib; BR: bendamustine rituximab; IR: ibrutinib rituximab; VO: venetoclax obinutuzumab; CO: chlorambucil obinutuzumab; FCR: fludarabine cyclophosphamide rituximab; CR: complete remission; OS: overall survival; PFS: progression free survival; ORR: overall response rate; MRD: minimal residual disease.
\end{abstract}

\section{Acknowledgements}

We are grateful for the support from Professor Yongping Song of the Affiliated Cancer Hospital of Zhengzhou University, Zhengzhou, China.

\section{Authors' contributions}

DL designed the study and drafted the manuscript. DL and JZ prepared the table. All authors participated in the revision of the manuscript. Both authors read and approved the final manuscript.

\section{Funding}

The study is partly supported by the Affiliated First Hospital of Zhengzhou University, Zhengzhou, China

\section{Availability of data and materials}

The material supporting the conclusion of this review has been included within the article.

\section{Ethics approval and consent to participate}

This is not applicable for this review.

\section{Consent for publication}

This is not applicable for this review.

\section{Competing interests}

$\mathrm{DL}$ serves on the speaker bureau for pharmacyclics.

\section{Author details}

${ }^{1}$ Division of Hematology \& Oncology, New York Medical College, Valhalla, NY 10595, USA. ${ }^{2}$ Department of Oncology, The First Affiliated Hospital of Zhengzhou University, Zhengzhou 450052, China.

Received: 15 June 2019 Accepted: 19 July 2019

Published online: 17 August 2019

\section{References}

1. Gribben JG. How I treat CLL up front. Blood. 2010;115(2):187-97.

2. Weide R, Feiten S, Chakupurakal G, Friesenhahn V, Kleboth K, Köppler H, Lutschkin J, Thomalla J, van Roye C, Heymanns J. Survival improvement of patients with chronic lymphocytic leukemia (CLL) in routine care 1995-2017. Blood. 2018;132(Suppl 1):4823.

3. Hijiya N, Suttorp M. How I treat chronic myeloid leukemia in children and adolescents. Blood. 2019;133(22):2374-84.

4. Rummel MJ, Niederle N, Maschmeyer G, Banat GA, von Grunhagen U, Losem C, Kofahl-Krause D, Heil G, Welslau M, Balser C, Kaiser U, Weidmann E, Durk H, Ballo H, Stauch M, Roller F, Barth J, Hoelzer D, Hinke A, Brugger W. Study group indolent L: bendamustine plus rituximab versus $\mathrm{CHOP}$ plus rituximab as first-line treatment for patients with indolent and mantle-cell lymphomas: an open-label, multicentre, randomised, phase 3 non-inferiority trial. Lancet. 2013;381(9873):1203-10.

5. Fischer K, Bahlo J, Fink AM, Goede V, Herling CD, Cramer P, Langerbeins $P$, von Tresckow J, Engelke A, Maurer C, Kovacs G, Herling M, Tausch E, Kreuzer K-A, Eichhorst B, Böttcher S, Seymour JF, Ghia P, Marlton P, Kneba M,
Wendtner C-M, Döhner H, Stilgenbauer S, Hallek M. Long-term remissions after FCR chemoimmunotherapy in previously untreated patients with CLL: updated results of the CLL8 trial. Blood. 2016;127(2):208-15.

6. Brown JR, O'Brien S, Kingsley CD, Eradat H, Pagel JM, Hirata J, Mclver T, Morariu-Zamfir R, Kipps TJ. Durable remissions with obinutuzumab-based chemoimmunotherapy: long-term follow-up of the phase $1 \mathrm{~b}$ GALTON trial in CLL. Blood. 2019;133(9):990-2.

7. Vitale C, Falchi L, Ciccone M, Burger J, Pemmaraju N, Borthakur G, Wierda WG, Keating MJ, Ferrajoli A. Ofatumumab is safe and effective as frontline treatment in older patients with chronic lymphocytic leukemia and severe co-morbidities, including other malignancies. J Geriatr Oncol. 2019. https://doi.org/10.1016/j.jgo.2019.1004.1002.

8. Liu B, Song Y, Liu D. Clinical trials of CAR-T cells in China. J Hematol Oncol. 2017;10(1):166.

9. Wang Z, Wu Z, Liu Y, Han W. New development in CAR-T cell therapy. J Hematol Oncol. 2017;10(1):53.

10. Wei G, Ding L, Wang J, Hu Y, Huang H. Advances of CD19-directed chimeric antigen receptor-modified T cells in refractory/relapsed acute lymphoblastic leukemia. Exp Hematol Oncol. 2017;6(1):10.

11. Zhang C, Liu J, Zhong JF, Zhang X. Engineering CAR-T cells. Biomark Res. 2017;5(1):22.

12. Zhang L-N, Song Y, Liu D. CD19 CAR-T cell therapy for relapsed/refractory acute lymphoblastic leukemia: factors affecting toxicities and long-term efficacies. J Hematol Oncol. 2018;11(1):41.

13. Zhao J, Lin Q, Song Y, Liu D. Universal CARs, universal T cells, and universal CART cells. J Hematol Oncol. 2018;11(1):132

14. Porter D, Frey N, Wood PA, Weng Y, Grupp SA. Grading of cytokine release syndrome associated with the CART cell therapy tisagenlecleucel. J Hematol Oncol. 2018;11(1):35.

15. Porter DL, Hwang WT, Frey NV, Lacey SF, Shaw PA, Loren AW, Bagg A, Marcucci KT, Shen A, Gonzalez V, Ambrose D, Grupp SA, Chew A, Zheng Z, Milone MC, Levine BL, Melenhorst JJ, June CH. Chimeric antigen receptor T cells persist and induce sustained remissions in relapsed refractory chronic lymphocytic leukemia. Sci Transl Med. 2015;7(303):303ra139.

16. Porter DL, Kalos M, Zheng Z, Levine B, June C. Chimeric antigen receptor therapy for b-cell malignancies. J Cancer. 2011;2:331-2.

17. Porter DL, Levine BL, Kalos M, Bagg A, June $\mathrm{CH}$. Chimeric antigen receptor-modified T cells in chronic lymphoid leukemia. N Engl J Med. 2011;365(8):725-33

18. Wendtner C-M. Ibrutinib: the home run for cure in CLL? Blood. 2019;133(19):2003-4.

19. Patel V, Balakrishnan K, Bibikova E, Ayres M, Keating MJ, Wierda WG, Gandhi V. Comparison of acalabrutinib, a selective Bruton tyrosine kinase inhibitor, with ibrutinib in chronic lymphocytic leukemia cells. Clin Cancer Res. 2017;23(14):3734-43.

20. Byrd JC, Harrington B, O'Brien S, Jones JA, Schuh A, Devereux S, Chaves J, Wierda WG, Awan FT, Brown JR, Hillmen P, Stephens DM, Ghia P, Barrientos JC, Pagel JM, Woyach J, Johnson D, Huang J, Wang X, Kaptein A, Lannutti BJ, Covey T, Fardis M, McGreivy J, Hamdy A, Rothbaum W, Izumi R, Diacovo TG, Johnson AJ, Furman RR. Acalabrutinib (ACP-196) in relapsed chronic lymphocytic leukemia. N Engl J Med. 2016;374(4):323-32.

21. Byrd JC, Brown JR, O'Brien S, Barrientos JC, Kay NE, Reddy NM, Coutre S, Tam CS, Mulligan SP, Jaeger U, Devereux S, Barr PM, Furman RR, Kipps TJ, Cymbalista F, Pocock C, Thornton P, Caligaris-Cappio F, Robak T, Delgado J, Schuster SJ, Montillo M, Schuh A, de Vos S, Gill D, Bloor A, Dearden C, Moreno C, Jones JJ, Chu AD, et al. Ibrutinib versus ofatumumab in previously treated chronic lymphoid leukemia. N Engl J Med. 2014;371(3):213-23.

22. Byrd JC, Furman RR, Coutre SE, Flinn IW, Burger JA, Blum KA, Grant B, Sharman JP, Coleman M, Wierda WG, Jones JA, Zhao W, Heerema NA, Johnson AJ, Sukbuntherng J, Chang BY, Clow F, Hedrick E, Buggy JJ, James DF, O'Brien S. Targeting BTK with ibrutinib in relapsed chronic lymphocytic leukemia. N Engl J Med. 2013;369(1):32-42.

23. Rai KR, Peterson BL, Appelbaum FR, Kolitz J, Elias L, Shepherd L, Hines J, Threatte GA, Larson RA, Cheson BD, Schiffer CA. Fludarabine compared with chlorambucil as primary therapy for chronic lymphocytic leukemia. N Engl J Med. 2000;343(24):1750-7.

24. Eichhorst BF, Busch R, Stilgenbauer S, Stauch $M$, Bergmann MA, Ritgen M, Kranzhofer N, Rohrberg R, Soling U, Burkhard O, Westermann A, Goede V, Schweighofer CD, Fischer K, Fink AM, Wendtner CM, Brittinger G, Dohner H, Emmerich B, Hallek M. German CLLSG: first-line therapy 
with fludarabine compared with chlorambucil does not result in a major benefit for elderly patients with advanced chronic lymphocytic leukemia. Blood. 2009;114(16):3382-91.

25. Burger JA, Tedeschi A, Barr PM, Robak T, Owen C, Ghia P, Bairey O, Hillmen P, Bartlett NL, Li J, Simpson D, Grosicki S, Devereux S, McCarthy H, Coutre S, Quach H, Gaidano G, Maslyak Z, Stevens DA, Janssens A, Offner F, Mayer J, O'Dwyer M, Hellmann A, Schuh A, Siddiqi T, Polliack A, Tam CS, Suri $\mathrm{D}$, Cheng $\mathrm{M}$, et al. Ibrutinib as initial therapy for patients with chronic lymphocytic leukemia. N Engl J Med. 2015;373(25):2425-37.

26. Woyach JA, Ruppert AS, Heerema NA, Zhao W, Booth AM, Ding W, Bartlett NL, Brander DM, Barr PM, Rogers KA, Parikh SA, Coutre S, Hurria A, Brown JR, Lozanski G, Blachly JS, Ozer HG, Major-Elechi B, Fruth B, Nattam S, Larson RA, Erba H, Litzow M, Owen C, Kuzma C, Abramson JS, Little RF, Smith SE, Stone RM, Mandrekar SJ, et al. Ibrutinib regimens versus chemoimmunotherapy in older patients with untreated CLL. N Engl J Med. 2018;379(26):2517-28.

27. Chai-Adisaksopha C, Brown JR. FCR achieves long-term durable remissions in patients with IGHV-mutated CLL. Blood. 2017;130(21):2278-82.

28. Shanafelt TD, Wang V, Kay NE, Hanson CA, O'Brien SM, Barrientos JC, Erba HP, Stone RM, Litzow MR, Tallman MS. A randomized phase III study of ibrutinib (PCl-32765)-based therapy vs standard fludarabine, cyclophosphamide, and rituximab (FCR) chemoimmunotherapy in untreated younger patients with chronic lymphocytic leukemia (CLL): a trial of the ECOG-ACRIN cancer research group (E1912). Blood. 2018;132(Suppl 1):LBA-4.

29. Goede V, Fischer K, Busch R, Engelke A, Eichhorst B, Wendtner CM, Chagorova T, de la Serna J, Dilhuydy M-S, IIImer T, Opat S, Owen CJ, Samoylova O, Kreuzer K-A, Stilgenbauer S, Döhner H, Langerak AW, Ritgen M, Kneba M, Asikanius E, Humphrey K, Wenger M, Hallek M. Obinutuzumab plus chlorambucil in patients with CLL and coexisting conditions. N Engl J Med. 2014:370(12):1101-10.

30. Moreno C, Greil R, Demirkan F, Tedeschi A, Anz B, Larratt L, Simkovic M, Samoilova O, Novak J, Ben-Yehuda D, Strugov V, Gill D, Gribben JG, Hsu E, Lih CJ, Zhou C, Clow F, James DF, Styles L, Flinn IW. Ibrutinib plus obinutuzumab versus chlorambucil plus obinutuzumab in first-line treatment of chronic lymphocytic leukaemia (iLLUMINATE): a multicentre, randomised, open-label, phase 3 trial. Lancet Oncol. 2019;20(1):43-56.

31. Jain $N$, Keating M, Thompson P, Ferrajoli A, Burger J, Borthakur G, Takahashi K, Estrov Z, Fowler N, Kadia T, Konopleva M, Alvarado Y, Yilmaz M, DiNardo C, Bose P, Ohanian M, Pemmaraju N, Jabbour E, Sasaki K, Kanagal-Shamanna R, Patel K, Jorgensen J, Garg N, Wang X, Sondermann K, Cruz N, Wei C, Ayala A, Plunkett W, Kantarjian H, et al. Ibrutinib and venetoclax for first-line treatment of CLL. N Engl I Med. 2019;380(22):2095-103.

32. Fischer K, Al-Sawaf O, Bahlo J, Fink A-M, Tandon M, Dixon M, Robrecht S, Warburton S, Humphrey K, Samoylova O, Liberati AM, Pinilla-lbarz J, Opat
S, Sivcheva L, Le Dû K, Fogliatto LM, Niemann CU, Weinkove R, Robinson S, Kipps TJ, Boettcher S, Tausch E, Humerickhouse R, Eichhorst B, Wendtner C-M, Langerak AW, Kreuzer K-A, Ritgen M, Goede V, Stilgenbauer S, et al. Venetoclax and obinutuzumab in patients with CLL and coexisting conditions. N Engl J Med. 2019;380(23):2225-36.

33. Langerak AW, Ritgen M, Goede V, Robrecht S, Bahlo J, Fischer K, Steurer $M$, Trněný M, Mulligan SP, Mey UJM, Trunzer K, Fingerle-Rowson G, Humphrey K, Stilgenbauer S, Böttcher S, Brüggemann M, Hallek M, Kneba $M$, van Dongen JJM. Prognostic value of MRD in CLL patients with comorbidities receiving chlorambucil plus obinutuzumab or rituximab. Blood. 2019;133(5):494-7.

34. Thompson PA. MRD negativity as a surrogate for PFS in CLL? Blood. 2018;131(9):943-4.

35. Kovacs G, Robrecht S, Fink AM, Bahlo J, Cramer P, Tresckow J, Maurer C, Langerbeins P, Fingerle-Rowson G, Ritgen M, Kneba M, Döhner H, Stilgenbauer S, Klapper W, Wendtner C-M, Fischer K, Hallek M, Eichhorst B, Böttcher S. Minimal residual disease assessment improves prediction of outcome in patients with chronic lymphocytic leukemia (CLL) who achieve partial response: comprehensive analysis of two phase III studies of the German CLL study group. J Clin Oncol. 2016;34(31):3758-65.

36. Thompson PA, Wierda WG. Eliminating minimal residual disease as a therapeutic end point: working toward cure for patients with CLL. Blood. 2016;127(3):279-86

37. Smith MR, Weiss R. Parametric modeling of "chemotherapy-free" regimens in CLL. Blood. 2018;132(Suppl 1):5555.

38. Eichhorst B, Fink AM, Bahlo J, Busch R, Kovacs G, Maurer C, Lange E, Koppler H, Kiehl M, Sokler M, Schlag R, Vehling-Kaiser U, Kochling G, Ploger C, Gregor M, Plesner T, Trneny M, Fischer K, Dohner H, Kneba M, Wendtner CM, Klapper W, Kreuzer KA, Stilgenbauer S, Bottcher S, Hallek M, International group of i, German CLLSG. First-line chemoimmunotherapy with bendamustine and rituximab versus fludarabine, cyclophosphamide, and rituximab in patients with advanced chronic lymphocytic leukaemia (CLL10): an international, open-label, randomised, phase 3, non-inferiority trial. Lancet Oncol. 2016;17(7):928-42.

39. Awan FT, Schuh A, Brown JR, Furman RR, Pagel JM, Hillmen P, Stephens DM, Woyach J, Bibikova E, Charuworn P, Frigault MM, Hamdy A, Izumi R, Linghu B, Patel P, Wang MH, Byrd JC. Acalabrutinib monotherapy in patients with chronic lymphocytic leukemia who are intolerant to ibrutinib. Blood Adv. 2019;3(9):1553-62.

40. Khan Y, O'Brien S. Acalabrutinib and its use in treatment of chronic lymphocytic leukemia. Future Oncol. 2019;15(6):579-89.

\section{Publisher's Note}

Springer Nature remains neutral with regard to jurisdictional claims in published maps and institutional affiliations.
Ready to submit your research? Choose BMC and benefit from:

- fast, convenient online submission

- thorough peer review by experienced researchers in your field

- rapid publication on acceptance

- support for research data, including large and complex data types

- gold Open Access which fosters wider collaboration and increased citations

- maximum visibility for your research: over $100 \mathrm{M}$ website views per year

At BMC, research is always in progress.

Learn more biomedcentral.com/submissions 